\title{
On the phase angle role in the shear response of ZK60 Mg alloys under multiaxial fatigue
}

\author{
Seyyed Mohamad Hasan Karparvarfard ${ }^{1,1}$, Seyed Behzad Behravesh ${ }^{1}$, Sugrib Kumar \\ Shaha ${ }^{1}$, and Hamid Jahed $^{1}$ \\ ${ }^{1}$ Deparment of Mechanical \& Mechatronics Engineering, University of Waterloo, 200 University Ave \\ W, Waterloo, ON N2L 3G1, Canada
}

\begin{abstract}
Proportional and non-proportional multiaxial fatigue tests are conducted on the closed-die forged ZK60 extrusion. The shear strain amplitude was kept constant at $0.5 \%$ for all the tests, while two different axial strain amplitudes of $0.4 \%$ and $0.7 \%$ were considered. At the higher strain amplitude $(0.7 \%)$ significant difference was observed between the torque amplitudes of proportional and non-proportional tests, whereas the axial load amplitude responses remained the same regardless of the phase angle shifts. It is likely that as the phase angle changes from $0-90$, the twin volume fraction at the peak shear strain decreases resulting in higher torque responses. On the other hand, at the lower strain amplitude, i.e. $0.4 \%$, where twinning is not active, phase angle does not show any effect on the shear response. An energy-based fatigue model is employed that effectively explains the different damage contributions by the axial and torsional loadings at different strain amplitudes, and accurately predicts the proportional and non-proportional multiaxial fatigue lives.
\end{abstract}

\section{Introduction}

Concerns over the adverse impact of high fuel consumption have led the transportation sector to adopt light weight alloys in their products. Magnesium $(\mathrm{Mg})$ as the lightest commercial metal was found to be a proper candidate for this purpose [1]. However, to employ Mg alloys in load-bearing components, it is imperative to study their behaviour under multi-axial loadings, as such loadings are very common in vehicle systems.

Die-casting is the dominant processing method of $\mathrm{Mg}$ alloys for its economic benefits [2]. Yet, it makes a lot of defects and porosities in the microstructure of the material, which adversely affects its mechanical behaviour. Hence, wrought $\mathrm{Mg}$ alloys are gaining interests to be utilized for their higher strength and finer grains [3]-[5].

The multiaxial fatigue characteristics of different wrought $\mathrm{Mg}$ alloys have recently been investigated. The effect of phase angle on the mechanical behaviour of these alloys are studied, and it was reported that the non-proportionality has no effect on their fatigue life [6]-[9] . However, to the best knowledge of the authors, the literature on the biaxial fatigue characteristics of wrought $\mathrm{Mg}$ alloys is restricted to the $\mathrm{AZ}$ and $\mathrm{AM}$ families. On the other 
hand, ZK60 is a forgeable Mg alloy whose mechanical properties in the forged state have been recently investigated, comprehensively [10]-[13]. Forging is a manufacturing technique that not only brings about fine grains and thereby higher strength, but also facilitates manufacturing by forming components with complicated geometries. In this study, we investigate the effect of phase angle on the shear response of closed-die forged ZK60 extrusion. Also, an energy-based model is employed that can accurately predict the proportional and nonproportional fatigue lives.

\section{Material and experiments}

The starting material in this study was ZK60 extrusion, supplied by Luxfer MEL Technologies in the form of cylindrical billets with $300 \mathrm{~mm}$ diameter. The chemical composition is presented in Table 1. Cylindrical billets with the diameter of $63.5 \mathrm{~mm}$ and length of $65 \mathrm{~mm}$ were extracted out of the as-received material. The billets were heated to the temperature of $250{ }^{\circ} \mathrm{C}$, which was the lowest temperature to achieve crack-free forged samples [14]. The billets were forged into an I-beam [15] at the ram speed of $20 \mathrm{~mm} / \mathrm{sec}$. Graphite was utilized as the lubricant to reduce the friction between the dies and billet during the process. The forged sample was air-cooled to the room temperature. Fig. 1(a) schematically shows the configuration of the forging die and the billet, and Fig. 1(b) depicts the final I-beam forged part. FD, LD, and TD, as shown in Fig. 1(b), denote the forging, longitudinal, and transverse directions.

Table 1. Chemical composition of ZK60 extrusion alloy (wt\%)

\begin{tabular}{|c|c|c|c|c|}
\hline Element & $\mathrm{Zn}$ & $\mathrm{Zr}$ & others & $\mathrm{Mg}$ \\
\hline Composition & 5.8 & 0.61 & $<0.30$ & balance \\
\hline
\end{tabular}

(b)

(a)
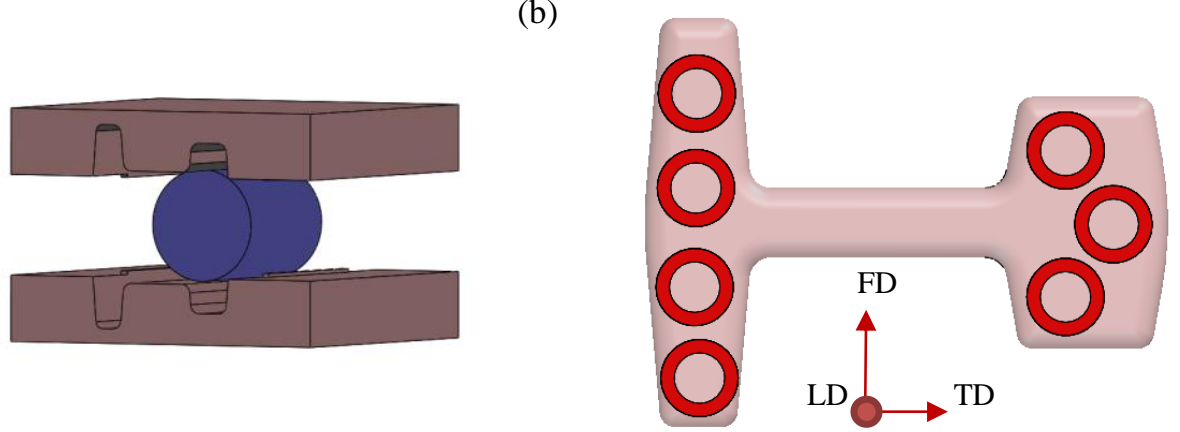

Fig. 1. The schematic representation of the (a) initial billet between the dies and (b) the final forged part and the location of thin-walled tubular specimens extracted from it

Thin-walled tubular specimens were machined along the LD as shown in Fig.1(b) with the geometry in accordance with the ASTM E2207 standard [16], as depicted in Fig 2. To avoid excessive deformation of the grip section, steel inserts were used. Proportional, $45^{\circ}$ and $90^{\circ}$ out-of-phase non-proportional fully-reversed cyclic tests were conducted using an Instron 8874 servo-hydraulic frame having axial and torsional load capacities of $\pm 25 \mathrm{kN}$ and \pm 100 N.m, respectively, under standard laboratory conditions. An epsilon biaxial extensometer with the axial and shear strain travels of $\pm 5 \%$ and $\pm 1.5^{\circ}$ was employed to control strains during the tests. The shear strain amplitude was kept constant at $0.5 \%$ for all the tests while two different axial strain amplitudes of $0.4 \%$ and $0.7 \%$ were considered. 
Fatigue tests were done at the frequency of $0.3 \mathrm{~Hz}$ for the lower axial strain amplitude and $0.1 \mathrm{~Hz}$ for the higher one. The failure criterion was $50 \%$ drop in the maximum load/ torsion, or the final rupture of the specimen, whichever happened first. Tests at each load level were repeated at least once to ensure the reproducibility of the results.

Texture measurement was achieved via a Bruker D8 Discover X-ray diffractometer equipped with a 2D-detector using $\mathrm{CuK \alpha}$ beam at $40 \mathrm{kV}$ and $40 \mathrm{~mA}$.

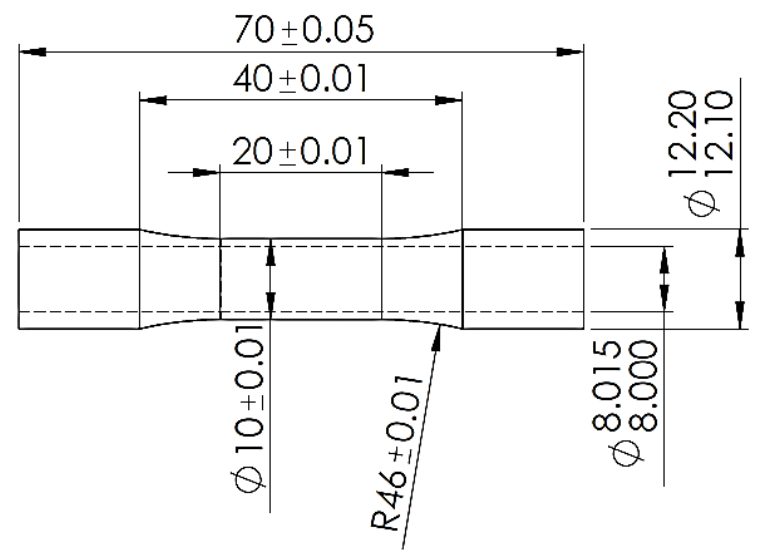

Fig. 2 Thin-walled tubular specimens' geometry (all dimensions are “mm”)

\section{Results and discussion}

\subsection{Texture}

Fig. 3 depicts the calculated (0002) and (1010) pole figures of samples extracted from the tall and short flanges of the I-beam.

(a)

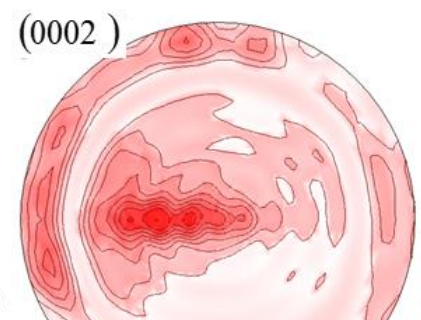

$\mathrm{TD}$

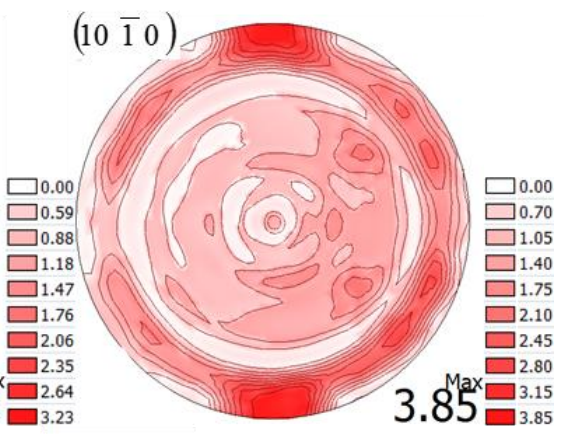


(b)
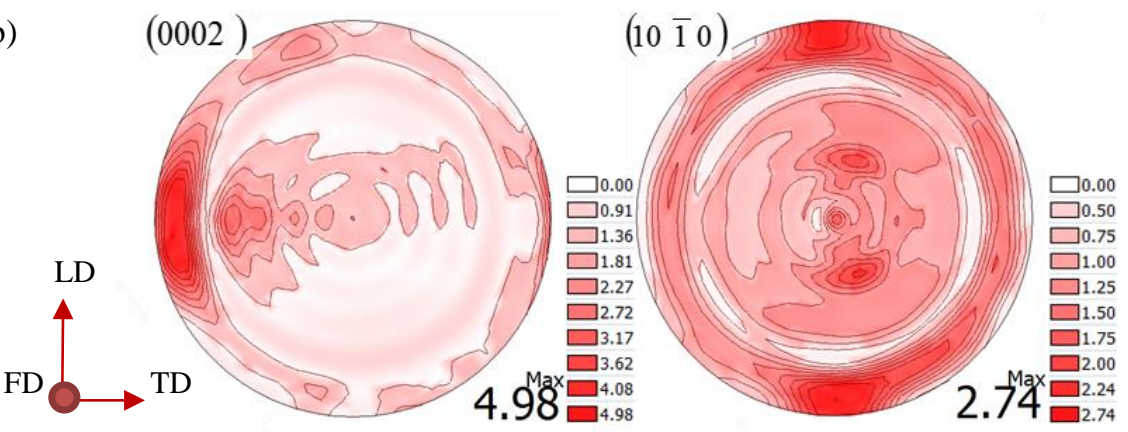

Fig. 3. (0002) and (1010) pole figures for the forged ZK60 I-beam extrusion samples extracted from (a) the tall flange and (b) the short flange

According to Fig. 3, the large plastic deformation as a result of the forging process brings about a sharp basal texture in the material. This sharp texture is due to the rotational dynamic recrystallization (RDRX), which causes the hexagonal closed pack (HCP) grains to rotate [17][13]. The sharp texture at both flanges, which indicate that the c-axis of most of the grains are perpendicular to the $\mathrm{LD}$, can give rise to the activation of extension twinning upon compression along this direction [18].

\subsection{Multiaxial fatigue behaviour}

\subsubsection{Uniaxial and pure shear loading}

Smooth and flat dog-bone samples with the gauge geometry presented in [19] and the length of $70 \mathrm{~mm}$ were machined out of the I-beam flanges. Fully reversed axial cyclic tests under strain control mode were performed at two different strain amplitudes of $0.4 \%$ and $0.7 \%$. The typical engineering strain-stress hysteresis loops for the second and half-life cycles are depicted in Fig. 4. As can be seen from Fig. 4, the hysteresis loop at the strain amplitude of $0.4 \%$ is symmetric, while at the higher strain amplitude, it tends to be sigmoidal. It has been reported that this tension-compression asymmetry stems from the activation of extension twins in the highly sharp textured wrought $\mathrm{Mg}$ alloys [20][21]. On the other hand, the symmetric hysteresis loop at the strain amplitude of $0.4 \%$ is because of the slip deformation being the dominant plastic deformation mechanism [22].

(a)

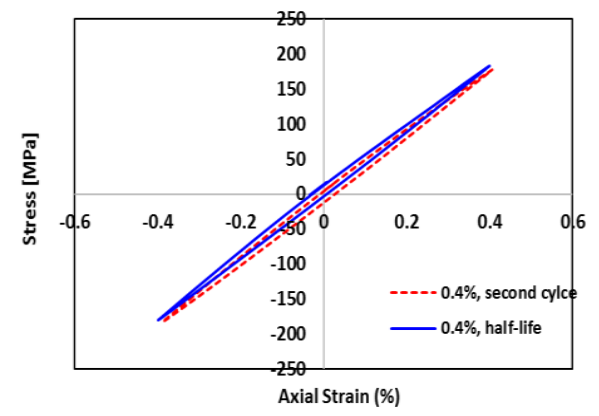

(b)

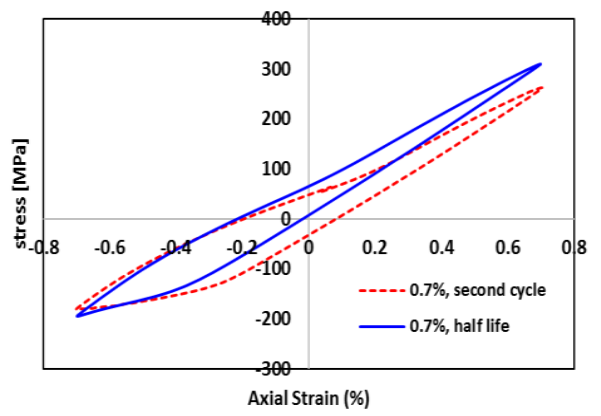

Fig. 4. Second cycle and half-life hysteresis loops of forged ZK60 extrusion under axial strain amplitude of a) $0.4 \%$, b) $0.7 \%$ 
Apart from the uniaxial tests, fully reversed cyclic pure shear test was also conducted on the tubular samples. Fig. 5 shows the pure shear response at the shear strain amplitude of $0.5 \%$. It is noted that the second and half life hysteresis are almost similar, and the hysteresis loop is symmetric with zero mean stress. As also elsewhere reported [9], the dominant deformation mechanism at such shear strain amplitude is believed to be the slip modes of deformation that lead to such symmetric response. The observed shear response revealed considerable amount of plastic deformation with the plastic strain energy density of 0.086 $\mathrm{MJ} / \mathrm{m}^{3}$, so $0.5 \%$ was selected as the shear strain amplitude for the multiaxial tests.

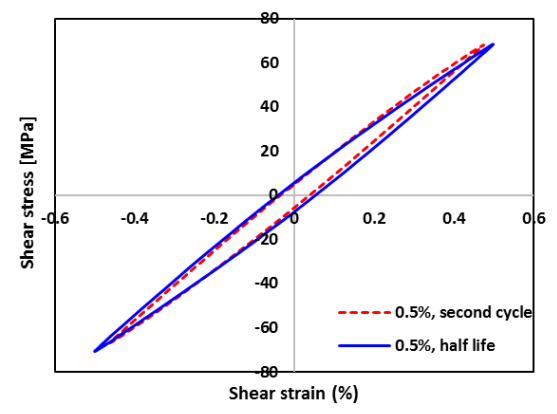

Fig. 5. Second cycle and half-life hysteresis loops of forged ZK60 extrusion under pure shear loading at the shear strain amplitude of $0.5 \%$

\subsubsection{Phase angle effect}

Proportional, $45^{\circ}$ and $90^{\circ}$ out-of-phase non-proportional fully-reversed multiaxial cyclic tests were conducted at the constant shear strain amplitude of $0.5 \%$, and axial strain amplitudes of $0.4 \%$ and $0.7 \%$. Fig. 6 represents the shear and axial responses of the forged material. At the higher strain amplitude of $0.7 \%$, significant difference was observed between the torque amplitudes of proportional and non-proportional tests, whereas the axial load amplitude responses remained the same regardless of the phase angle shifts. The in-phase tests showed the lowest torque amplitude response, followed by 45 , with 90 out-of-phase showing the highest torque response with an increase of close to $35 \%$ compared to in-phase. The typical hysteresis loops for the axial and shear responses are also separately shown in Fig. 7, where significant difference can be seen in the shear responses with different phase angles under the axial and shear strain amplitudes of $0.7 \%$ and $0.5 \%$, respectively (Fig. $7(\mathrm{~d})$ ).

(a)

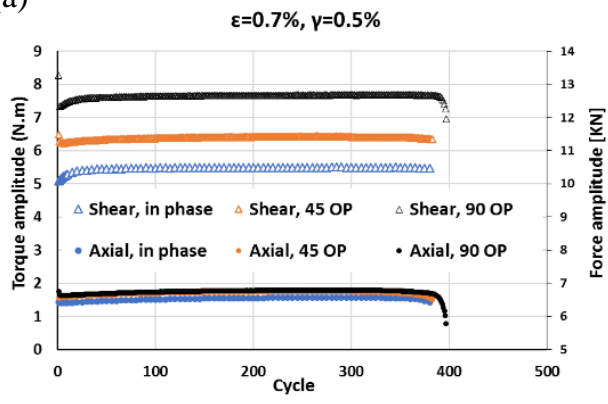

(b)

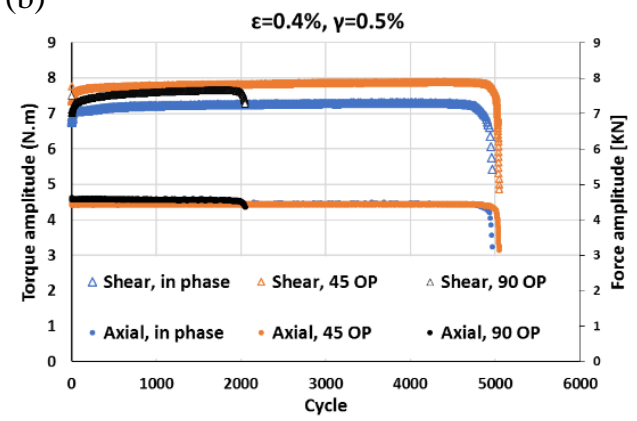


Fig. 6. Torque and axial force response in strain-controlled axial-torsional testing of forged ZK60 under (a) axial and shear strain amplitudes of $\varepsilon=0.7 \%$ and $\gamma=0.5 \%$; (b) axial and shear strain amplitudes of $\varepsilon=0.4 \%$ and $\nu=0.5 \%$

It is likely that as the phase angle changes from $0^{\circ}$ to $90^{\circ}$, the twin volume fraction at the peak shear strain decreases resulting in the higher torque responses. This can be better understood with depicting the simultaneous axial and torsional modes under the axial and shear strain amplitudes of $0.7 \%$ and $0.5 \%$, respectively, as shown in Fig. 8. According to this figure, the highest twin amount (the compressive axial peak) coincides with the peak of shear strain under the in-phase mode; however, shifting the phase angles toward $90^{\circ}$ leads to the lower volume of twins at the shear strain peaks. As was elsewhere reported [9], the basal slip is more favourable in the re-orientated grains of the microstructure than the matrix; thereby, higher twin volume fraction yields in a lower torque amplitude needed to accommodate the shear strain under the torsional mode. On the other hand, at the lower strain amplitude, i.e. $0.4 \%$, where twinning is not active, phase angle does not show any effect on the shear response.

(a)

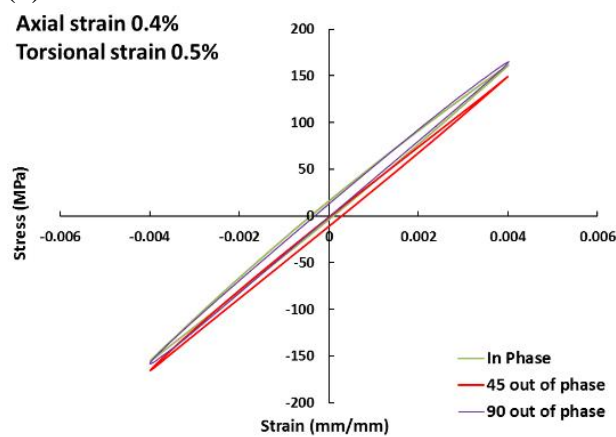

(c)

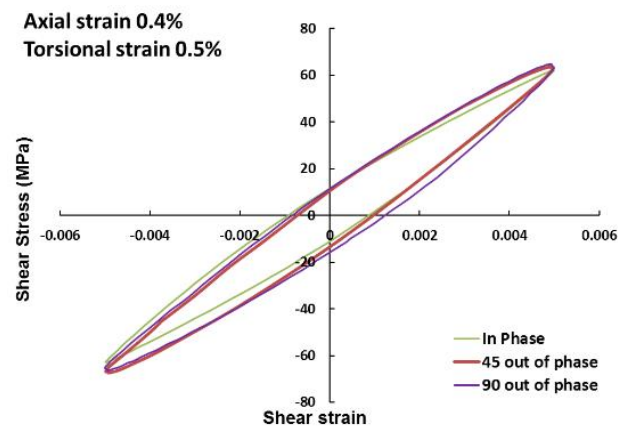

(b)

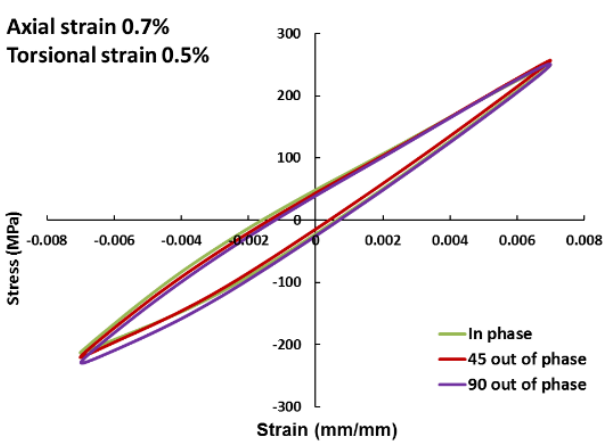

(d)

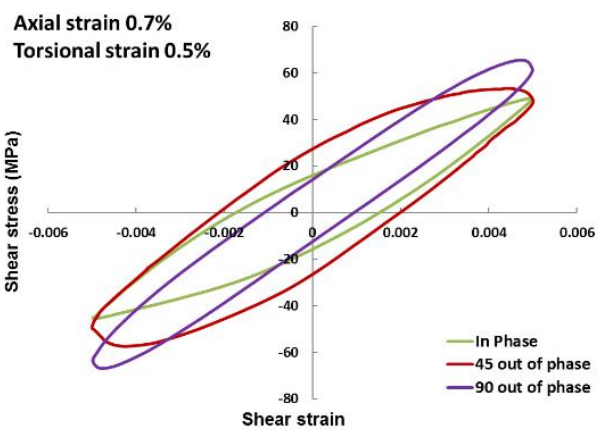

Fig. 7. Half-life axial (a,b) and torsional (c,d) hysteresis loops of forged ZK60 extrusion under multiaxial loading at the constant shear strain amplitude of $0.5 \%$ and axial strain amplitudes of $0.4 \%$ $(\mathrm{a}, \mathrm{c})$ and $0.7 \%(\mathrm{~b}, \mathrm{~d})$

Moreover, comparing the shear responses under the axial strain amplitudes of $0.4 \%$ and $0.7 \%$, it is noted that the torque amplitudes under the higher strain amplitude $(0.7 \%)$ tend to be lower than those under the strain amplitude of $0.4 \%$ at the 0 and $45^{\circ}$ phase angle shifts. On the contrary, the torque amplitudes at the phase angle shift of $90^{\circ}$ remain almost similar regardless of the axial strain amplitude. It is believed that the simultaneous axial deformation affects the shear response [8],[9]. While for the cases of in-phase and $45^{\circ}$ out-of-phase, some axial strain is being accommodated at the peak of shear strain, in the case of $90^{\circ}$ out-of-phase, 
the axial strain amount in the shear strain peak time is zero, bringing about identical shear response under both $0.4 \%$ and $0.7 \%$ axial modes.

(a)

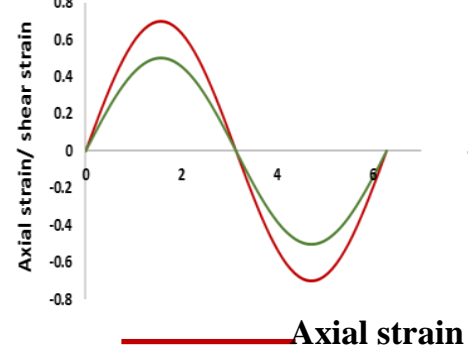

(b)

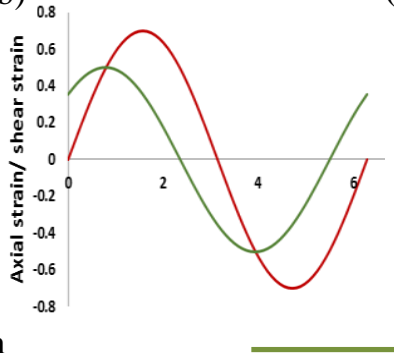

(c)

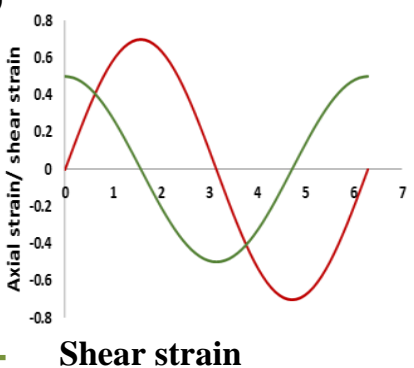

Fig. 8. Axial and torsional strains vs. time at (a) 0 , (b) $45^{\circ}$ out-of-phase, and (c) $90^{\circ}$ out-of-phase

\subsection{Fatigue modelling}

An energy-based model is employed that explains the damage contributions incurred by axial and torsional loading to predict the fatigue life under multiaxial loading [23]. According to this model, the total strain energy density is consisted on the positive elastic and plastic strain energy densities, which can be calculated as:

$$
\begin{gathered}
\Delta E_{e, A}^{+}=\frac{\sigma_{\text {max }}^{2}}{2 E} \\
\Delta E_{e, S}^{+}=\frac{\tau_{\text {max }}^{2}+\tau^{2}{ }_{\text {min }}}{2 G} \\
\Delta E_{p, A}=\oint_{c y c l e} \sigma_{x} d \varepsilon^{P}{ }_{x x} \\
\Delta E_{p, S}=2 \oint_{c y c l e} \tau_{x y} d \varepsilon^{P}{ }_{x y}
\end{gathered}
$$

where $\Delta E_{e, A}^{+}, \Delta E_{e, S}^{+}, \Delta E_{p, A}$, and $\Delta E_{p, S}$ are the positive elastic axial, positive elastic torsional, plastic axial, and plastic torsional strain energy densities, respectively. Also, $\sigma_{\max }$ and $\tau_{\max }$ are the peak stresses of the axial and torsional hysteresis loops associated with the half-life cycle, while $\tau_{\min }$ corresponds to the valley stress of the torsional mode's hysteresis loop. Lastly, E and G denote the axial and shear moduli of elasticity. The total axial and torsional strain energy densities are then related to the multiaxial fatigue life through:

$$
\begin{gathered}
\Delta E_{A}=E^{\prime}{ }_{e}\left(2 N_{A}\right)^{B}+E_{f}^{\prime}\left(2 N_{A}\right)^{C} \\
\Delta E_{S}=W^{\prime}{ }_{e}\left(2 N_{S}\right)^{B_{S}}+W_{f}^{\prime}\left(2 N_{S}\right)^{C_{S}}
\end{gathered}
$$




$$
N_{f}=\frac{\Delta E_{A}}{\Delta E_{T}} N_{A}+\frac{\Delta E_{S}}{\Delta E_{T}} N_{S}
$$

where $\Delta E_{T}$ is the summation of $\Delta E_{A}$ and $\Delta E_{S}$. Also, $N_{A}$ and $N_{S}$ correspond to the fatigue lives under pure axial and pure torsional loadings, respectively. Fig. 9 represents the correlation of the model-estimated life with the experimental lives.

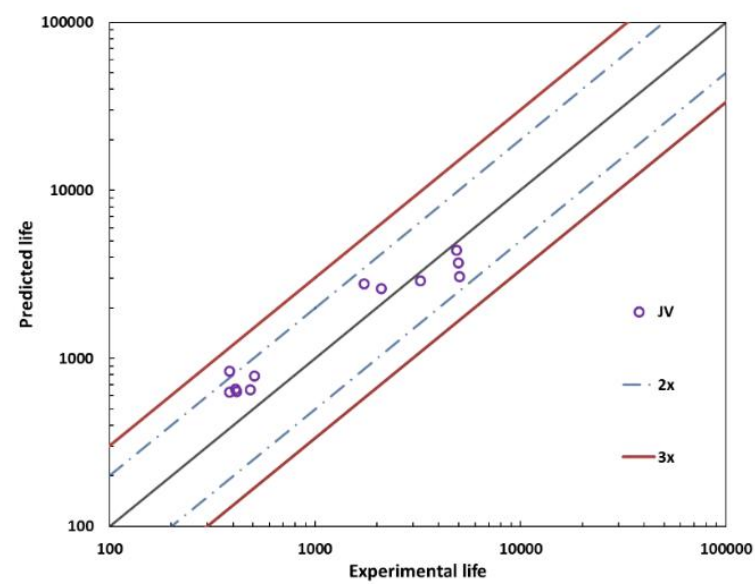

Fig. 9. The correlation of JV-estimated life with the experimental life

The authors would like to gratefully acknowledge the financial support of the Natural Sciences and Engineering Research Council of Canada, the Automotive Partnership Canada (APC) program. The authors would also like to thank Bruce Williams, Jonathan McKinley and Lucian Blaga from CanmentMATERIALS in Hamilton, Canada for performing the forging trials.

\section{References}

[1] B. L. Mordike and T. Ebert, "Magnesium Properties - applications - potential," Mater. Sci. Eng. A, 302, no. 1, pp. 37-45, 2001.

[2] F. Pan, M. Yang, and X. Chen, "A Review on Casting Magnesium Alloys : Modification of Commercial Alloys and Development of New Alloys," J. Mater. Sci. Technol., 32, no. 12, pp. 1211-1221, 2016.

[3] A. Hadadzadeh, M. A. Wells, S. Kumar, H. Jahed, and B. W. Williams, "Role of compression direction on recrystallization behavior and texture evolution during hot deformation of extruded ZK60 magnesium alloy," J. Alloys Compd., 702, pp. 274-289, 2017.

[4] A. A. Roostaei and H. Jahed, "Role of loading direction on cyclic behaviour characteristics of AM30 extrusion and its fatigue damage modelling," Mater. Sci. Eng. A, 670, pp. 26-40, 2016.

[5] Y. Z. Wu, H. G. Yan, J. H. Chen, S. Q. Zhu, B. Su, and P.-L. Zeng, "Microstructure and mechanical properties of ZK60 magnesium alloy fabricated by high strain rate multiple forging," Mater. Sci. Eng. A, 29, no. 1, pp. 54-59, 2013.

[6] J. Albinmousa and H. Jahed, "Multiaxial effects on LCF behaviour and fatigue failure of AZ31B magnesium extrusion," Int. J. Fatigue, 67, pp. 103-116, 2014. 
[7] H. Jahed and J. Albinmousa, "Multiaxial behaviour of wrought magnesium alloys A review and suitability of energy-based fatigue life model," Theor. Appl. Fract. Mech., 73, pp. 97-108, 2014.

[8] J. Albinmousa, H. Jahed, and S. Lambert, "Cyclic behaviour of wrought magnesium alloy under multiaxial load," Int. J. Fatigue, 33, no. 8, pp. 1127-1139, 2011.

[9] A. A. Roostaei and H. Jahed, "Multiaxial cyclic behaviour and fatigue modelling of AM30 Mg alloy extrusion," Int. J. Fatigue, 97, pp. 150-161, 2017.

[10] S. M. H. Karparvarfard, S. K. Shaha, S. B. Behravesh, H. Jahed, and B. W. Williams, "Microstructure, texture and mechanical behavior characterization of hot forged cast ZK60 magnesium alloy," J. Mater. Sci. Technol., 2017.

[11] H. SMH. Karparvarfard, S.K. Shaha, A. Hadadzadeh. S.B. behravesh, Jahed, M. A. Wells, and B. Williams, "Characterization of Semi-Closed Die-Forged ZK60 Mg Alloy Extrusion,” Magnes. Technol. 2017, pp. 329-334, 2017.

[12] S. M. H. Karparvarfard, S. K. Shaha, S. B. Behravesh, H. Jahed, and B. W. Williams, "Fatigue characteristics and modeling of cast and cast-forged ZK60 magnesium alloy," Int. J. Fatigue, 118, no. November 2017, pp. 282-297, 2019.

[13] S. Karparvarfard, S. K. Shaha, S. B. Behravesh, H. Jahed, and B. Williams, "Fatigue life improvement of cast ZK60 Mg alloy through low temperature closeddie forging for automotive applications," MATEC Web Conf., 165, p. 06009, 2018.

[14] N. Ogawa, M. Shiomi, and K. Osakada, "Forming limit of magnesium alloy at elevated temperatures for precision forging," Int. J. Mach. Tools Manuf., 42, no. 5, pp. 607-614, 2002.

[15] G. Yu, "Forging Specimen Design for Magnesium Alloys," (Master's Thesis), Retrieved from Univ. Waterloo Database, 2016.

[16] “ASTM E2207 - Standard Practice for Strain-Controlled Axial-Torsional Fatigue Testing with Thin-Walled Tubular Specimens," ASTM Int.

[17] Y. Xu-yue, J. I. Ze-sheng, H. Miura, and T. Sakai, "Dynamic recrystallization and texture development during hot deformation of magnesium alloy AZ31," Trans. Nonferrous Met. Soc. China, 19, no. 1, pp. 55-60, 2008.

[18] L. Wu, A. Jain, D. W. Brown, G. M. Stoica, S. R. Agnew, B. Clausen, D. E. Fielden, and P. K. Liaw, "Twinning-detwinning behavior during the straincontrolled low-cycle fatigue testing of a wrought magnesium alloy, ZK60A," Acta Mater., 56, no. 4, pp. 688-695, 2008.

[19] S. M. H. Karparvarfard, S. K. Shaha, S. B. Behravesh, H. Jahed, and B. W. Williams, "Microstructure, texture and mechanical behavior characterization of hot forged cast ZK60 magnesium alloy," J. Mater. Sci. Technol., 2017.

[20] M. H. Yoo, "Slip, twinning, and fracture in hexagonal close-packed metals," Metall. Trans. A, 12, no. 3, pp. 409-418, 1981.

[21] D. W. Brown, A. Jain, S. R. Agnew, and B. Clausen, "Twinning and Detwinning During Cyclic Deformation of Mg Alloy AZ31B,” Mater. Sci. Forum, 539-543, pp. 3407-3413, 2007.

[22] J. B. Jordon, J. B. Gibson, M. F. Horstemeyer, H. El Kadiri, J. C. Baird, and A. A. Luo, "Effect of twinning, slip, and inclusions on the fatigue anisotropy of extrusion-textured AZ61 magnesium alloy," Mater. Sci. Eng. A, 528, no. 22-23, pp. 6860-6871, 2011.

[23] H. Jahed, A. Varvani-Farahani, M. Noban, and I. Khalaji, “An energy-based fatigue life assessment model for various metallic materials under proportional and nonproportional loading conditions," Int. J. Fatigue, 29, no. 4, pp. 647-655, 2007. 